
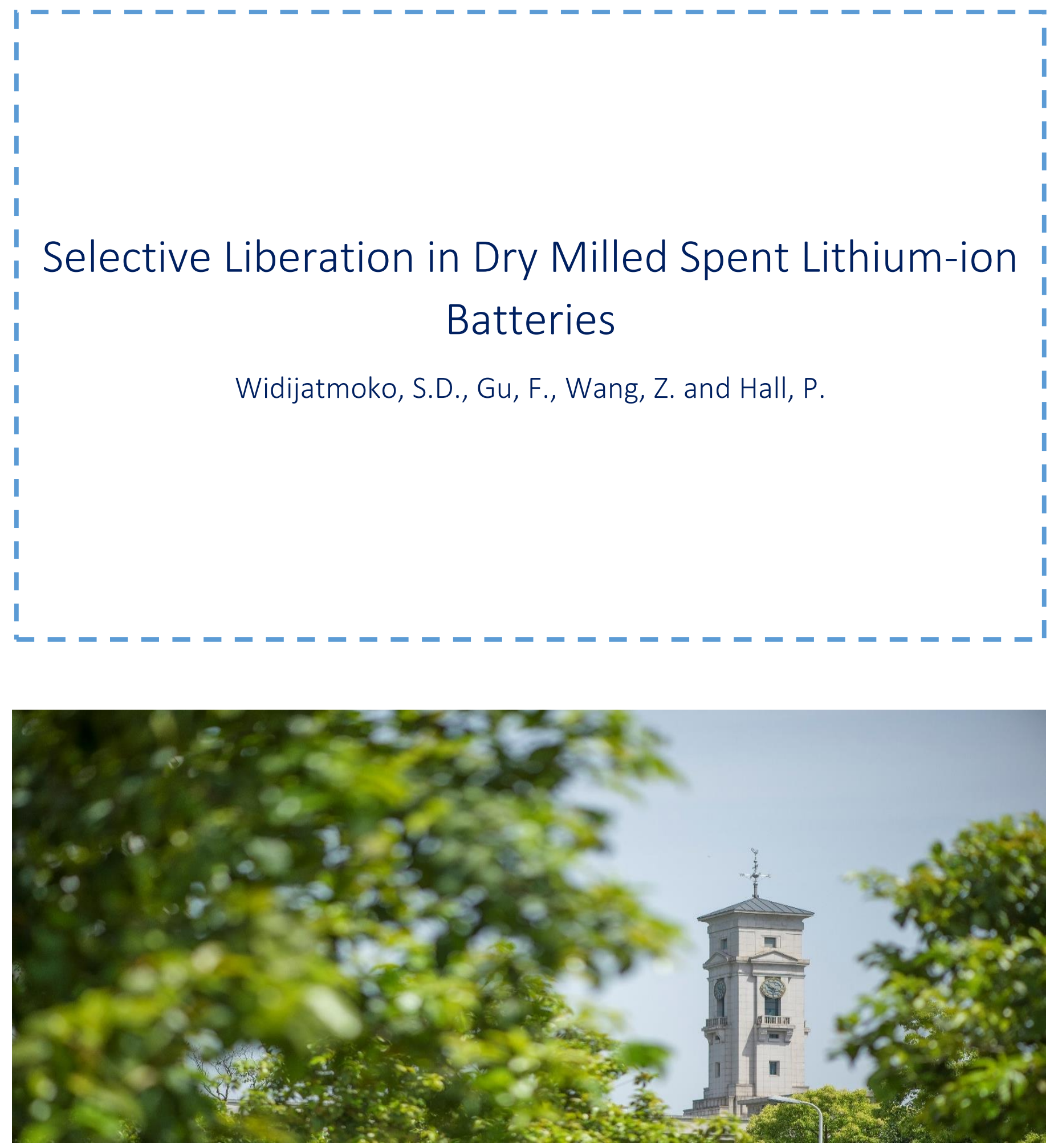
University of Nottingham Ningbo China, 199 Taikang East Road, Ningbo, 315100, Zhejiang, China.

First published 2019

This work is made available under the terms of the Creative Commons Attribution 4.0 International License:

http://creativecommons.org/licenses/by/4.0

The work is licenced to the University of Nottingham Ningbo China under the Global University Publication Licence:

https://www.nottingham.edu.cn/en/library/documents/researchsupport/global-university-publications-licence.pdf 


\title{
Selective Liberation in Dry Milled Spent Lithium-ion Batteries
}

\author{
Samuel D Widijatmoko ${ }^{a}$ Gu Fub,c ${ }^{b}$ Zheng Wang ${ }^{a}$, Philip Halla \\ aDepartment of Chemical and Environmental Engineering, University of Nottingham Ningbo, China \\ bDepartment of Industrial Engineering, Zhejiang University, Hangzhou 310027, China \\ cNational Institute of Innovation Management, Zhejiang University, Hangzhou 310027, China \\ *Corresponding Author, Department of Chemical and Environmental Engineering, University of Nottingham \\ Ningbo, China, 437 Peter Mansfield Building, 199 Taikang East Road Ningbo 315100, China \\ *E-mail: Philip.Hall@nottingham.edu.cn
}

\begin{abstract}
Lithium-ion batteries (LIBs) have an established role in the consumer electronics markets with minimum risk of replacement from any other contender in the near future. The recent momentum towards electric vehicles and the renewable energy storage market is creating an increased demand for LIBs. The large amount of hazardous waste generated from the disposal of LIBs is driving research into a sustainable approach for LIB treatment and recovery. The positive electrode active materials being the main targeted component as it is the greatest cost contributor to LIBs production. During the production of the positive electrode, a powder of active material typically Lithium Cobalt Oxide is applied to aluminium foil and held together using a polyvinylidene fluoride (PVDF) binder.
\end{abstract}

The recovery of positive electrode active material involves physical and chemical treatment. Where effective and efficient physical treatment would reduce the cost incurred for the subsequent chemical treatment. Mechanical treatment is an integral part of liberating and concentrating positive electrode active material. The positive electrode active materials have been reported are being concentrated in the finer size region. However, the cut point at which the positive electrode active material being concentrated is substantially greater than the size of the positive electrode active material particle size as found in spent LIBs.

This paper studies the characteristics of milled spent LIBs concerning particle size. The results suggest that a cut point of $850 \mu \mathrm{m}$ gives the best composition of the positive electrode active materials recovery that minimises the involvement of copper and aluminium. However, most of the active materials are still held together by the PVDF binder that creates a substantially higher cut point proposed that the actual size of the positive electrode active material contained within spent LIBs. The interaction of copper and aluminium current collector based on size also further discussed in this paper. A comparison between selective liberation in the new and spent LIBs has been made to 
assess the difference in mechanical properties that contribute to its overall liberation efficiency.

Keywords: lithium-ion battery; mechanical treatment; liberation; recycling; cathode 


\section{Introduction}

Electrical energy is the basis of our modern lifestyle. Batteries are currently being developed to power an increasingly diverse range of applications, from electric vehicles to smartwatches. Owing to its higher energy density, lightweight, and its relatively low cost, lithium-ion batteries (LIBs) are the predominant energy storage choice for many consumer electronics and electric grids [1]. Despite the advancement of battery technology, presently LIBs meet most of the requirements dictated by the large volume of applications linked to renewable energy and electric transportation field [2].

A battery pack may consist of one or several cells that can be connected in series or parallel. In its conventional form, the main component of a LIB cell comprises of graphite negative electrode (e.g. mesocarbon microbeads, MCMB) with copper foil as current collector, a positive electrode formed by lithium-transition metal-oxides ( $\mathrm{Li}-\mathrm{M}-\mathrm{O}_{2}$, e.g. $\mathrm{LiCOO}_{2}$ ) with an aluminium foil current collector, a liquid electrolyte consisting of lithium salts (e.g. LiPF6) in a mixed organic solvent (e.g. ethylene carbonate-dimethyl carbonate, EC-DMC), all imbedded in a separator layer (e.g. polypropylene/polyethylene, $\mathrm{PP} / \mathrm{PE}$ ). The active materials for the positive and negative electrodes are in powder form, cast onto the current collector and held by a binder, commonly polyvinyldene fluoride (PVDF) $[3,4]$.

As technology continues to develop, the demand for LIBs is expected to increase, which leads to a large amount of potential waste being generated. Spent LIBs are considered hazardous waste and should not be released into the environment [2]. The recent impetus of electric vehicle has become a driving force in LIBs recycling. Currently, LIBs recycling is hindered by the low collection rate [5]. In the past decade, LIBs that were contained within consumer electronics were relatively small in size and were generally stored by the consumer or disposed of improperly through the municipal waste stream at the end-of-life. However, the low collection rate may not be a problem in the future because of the sheer size of the electric vehicle battery [6]. There is the need to tackle this waste problem and promote a circular economy approach which can mitigate resource scarcity $[7,8]$. This has led to extensive research into processes for the recovery of valuable metals found in spent LIBs. From components used in the manufacturing of LIBs, positive electrode active materials being the main targeted component as it is where the most valuable resources are found [9].

The recovery of positive electrode active material involves physical and chemical processes [10]. Spent LIBs still contain some residual energy, which may cause a runaway reaction during recycling and therefore discharging is always a necessary step before further treatment $[11,12]$. Physical processes separate material according to different properties such as size, density, conductivity, magnetic properties, etc. [13]. 
The chemical processes may be classified into pyrometallurgical and hydrometallurgical processes. Hydrometallurgical treatment involves leaching, extraction, and chemical or electrochemical precipitation [14]. In contrast, pyrometallurgy feeds the spent LIBs into a furnace in which copper recovered as a mixed alloy product and the lithium and aluminium to the slag. Pyrometallurgy products also often recovered through hydrometallurgy [15].

Physical processes have always been a pre-treatment process in the field of LIBs recycling. Effective and efficient physical processes are required to minimise the energy consumption for the subsequent chemical processes. Mechanical liberation of spent LIBs has been reported to exhibit selective comminution, in which the positive electrode active materials are being concentrated in the finer size region with minimum contamination from other battery components [16-18]. Components such as iron are easily recovered through a magnetic separation after liberation $[13,19]$. Therefore, the components from mechanical liberation only concern the electrode active materials, polymeric material, copper and aluminium.

Selective liberation has been proposed and used to concentrate positive electrode active materials before further separation. The cut point proposed varies from $0.25 \mathrm{~mm}$ to $2 \mathrm{~mm}$ [19-22]. However, this cut point size range is substantially greater when compared to the positive electrode active materials powder found in LIBs (ca. $1.50 \mu \mathrm{m}-7.80 \mu \mathrm{m}$ ) [23]. Smaller cut point such as $0.25 \mathrm{~mm}$ has been reported to give high purity of positive electrode active material, but it only recovers $56.38 \%$ positive electrode active material [22]. Diekmann et al., [20] reveal that it is possible to re-grind the bigger size fraction to liberate the positive electrode active material further, resulting in $75 \mathrm{wt} \%$ recovery in size range of $<0.50 \mathrm{~mm}$. However, it comes with the expense of a closer particle size distribution that makes the size-based separation more challenging, and therefore, a third stage re-milling may not be a viable option.

In summary, shredding has been proposed and used to concentrate on the positive electrode active materials. Shredding of spent LIBs aims at exploiting selective liberation of positive electrode active materials as well as size range adjustment for subsequent separation processes [19-22]. The different cut point proposed previously may be attributed by a different type of milling machine and the parameters employed by different researchers. However, the understanding related to the characteristics of LIBs particles after shredding has not yet been thoroughly discussed. Much of the attention has been given to concentrate on positive electrode active materials with very little attention to the current collectors. 
Therefore, this research aims at understanding the characteristics of milled spent LIBs. The components of milled LIBs are divided into two constituents of leachable and nonleachable components. Assuming that leaching is the primary process after liberation and hence, the discussion will mainly be concerned with the key leachable components. The key leachable components include positive electrode active material and the copper and aluminium current collector. This research not only explores the selective liberation of positive electrodes active materials towards the current collectors, but also the selective liberations between the copper and aluminium current collectors. Moreover, as the LIB cell undergoes ageing, the current collectors and the binder experience degradation in terms of mechanical strength and the adhesiveness [24-26]. Therefore, the comparison of selective liberation of new and spent battery are made in this research. This comparison then allows the understanding of the effect of ageing towards the selective liberation and would be discussed further in this manuscript.

\section{Materials and method}

\subsection{Materials}

The spent LIBs used in this study were collected from local electronic repair shops within Ningbo China. All the spent batteries used were previously used in smartphones and came from a range of manufacturers to represent typical waste. Only prismatic LIBs with predominantly cobalt as positive electrode active materials were used. The type of active materials within a LIB can be identified by the marking available that follows $B S E N$ 61960-3:2017 [27]. This is identified by the "ICP" marking; the letter "I" designates the carbon negative electrode basis; the letter " $\mathrm{C}$ " designates the cobalt positive electrode basis; the letter " $P$ " designates the prismatic shape of the cell. Other designations for other types of positive and negative electrode basis as well as the shape of the cell can be found in BS EN 61960-3:2017. The types of positive electrode active material were identified by using an XRD (XRD - CuK $\alpha$, Bruker AXS D8 Advance), and it was found to be $\mathrm{LiCoO}_{2}$. For elemental analysis, analytical grade $\mathrm{HNO}_{3}, \mathrm{HCl}, \mathrm{H}_{2} \mathrm{O}_{2}$ (Jingrui, UP-S Grade), and water (Mili-Q) were used for the entire digestion and dilution.

At present, PVDF or SBR-CMC can be used as the binder for the negative electrode, while the positive electrode uses PVDF [28]. The type of the active material binder can be deduced by identifying the presence of fluorine atoms. and sodium atoms (that suggest SBR-CMC binder) by using a Scanning Electron Microscopy-Energy Dispersive X-Ray (SEM-EDX, Zeiss - Oxford/ Sigma VP) [29, 30]. It was found that only Fluorine was detected which shows PVDF was used as the negative electrode binder material. 


\subsection{Method}

Spent LIBs were first discharged by using 56 -ohm resistor until the voltage is near zero $(0.2 \mathrm{~V}-0.5 \mathrm{~V})$. Spent LIBs were then shredded in a Restch SM 2000 cutting mill with an $8 \mathrm{~mm}$ grid. The shredded LIBs were then dried in an oven at $80^{\circ} \mathrm{C}$ to constant weight to remove volatile organic electrolytes. Three representative samples of $69.8 \mathrm{~g}$ on average were prepared by using a riffle splitter. The sample then screened for iron using a rare earth magnet roll enclosed in polyvinyl chloride (PVC) pipe.

The three samples taken from the riffling exercise were analysed for particle size distribution using certified test sieve (Endecotts) and a fix amplitude shaker (Capco Inclino Sieve Shaker 3). The sieves used were with a nominal aperture diameter of $13200 \mu \mathrm{m}, 9500 \mu \mathrm{m}, 6700 \mu \mathrm{m}, 4750 \mu \mathrm{m}$, and then $2360 \mu \mathrm{m}, 850 \mu \mathrm{m}, 212 \mu \mathrm{m}$, and 38 $\mu \mathrm{m}$. Sieving with nominal aperture size greater than $4750 \mu \mathrm{m}$ was performed separately, and the sieves were brushed after every use to collect fine particles that are trapped between the joint of adjacent holes. All the sieves for size fraction less than $4750 \mu \mathrm{m}$ were put together to assess the particle size distribution. Each different size fraction then analysed for elemental content.

As a baseline comparison, new LIBs of the same type of the spent LIBs were purchased. These were subjected to the same treatment as the spent LIBs. $94.8 \mathrm{~g}$ of dried milled new LIBs were used in this study.

Samples were transferred to porcelain lidded crucibles and calcined in a muffle furnace to remove difficult to mill materials (e.g. polymer materials). The calcination was performed in multiple stages to prevent a sudden release of gas. The temperature was increased at a rate of $10^{\circ} \mathrm{C} \mathrm{min}^{-1}$ up to $350^{\circ} \mathrm{C}$ with $2 \mathrm{~h}$ holding time. Followed an increase in temperature at the same rate to $500^{\circ} \mathrm{C}$ with $3 \mathrm{~h}$ holding time. The sample was then allowed to cool to room temperature. The samples were then milled using a centrifugal mill (Retsch ZM 200) with a $0.25 \mathrm{~mm}$ grid. Samples from inside and outside the grid were collected and sieved using $212 \mu \mathrm{m}$ nominal aperture size, and the size fraction $>212 \mu \mathrm{m}$ was re-milled until the recovery rate $<212 \mu \mathrm{m}$ was $>95 \mathrm{wt} \%$. The samples that initially had particle sizes of $<212 \mu \mathrm{m}$ were excluded from the above steps.

The digestions were adapted from BS EN 62321-5:2014 [31]. Approximately $0.2 \mathrm{~g}$ of sample was weighed to four decimal places using an analytical balance. Microwave digester (CEM MARS 5) equipped with temperature control was used to digest the samples and dissolve the materials present to enable analysis. The digestion is carried out in multiple stages, and the details are summarised in Table 1. 
Table 1 - Microwave digestion parameters

\begin{tabular}{|c|c|c|c|c|c|c|}
\hline Stage & $\begin{array}{l}\text { Number of } \\
\text { Vessels }\end{array}$ & $\begin{array}{l}\text { Power } \\
\text { Level } \\
(\mathrm{W})\end{array}$ & $\begin{array}{l}\text { Ramp } \\
\text { Time } \\
\text { (min) }\end{array}$ & $\begin{array}{c}\text { Temperature } \\
\left({ }^{\circ} \mathrm{C}\right)\end{array}$ & $\begin{array}{l}\text { Hold } \\
\text { Time } \\
\text { (Min) }\end{array}$ & Description \\
\hline 1 & 8 & 800 & 8 & 80 & 2 & \multirow{2}{*}{$\begin{array}{l}\sim 0.2 \mathrm{~g} \text { of solid with } 1 \mathrm{ml} \\
\mathrm{H}_{2} \mathrm{O}+4 \mathrm{ml} \text { UP-S Grade } 68 \\
w t \% \mathrm{HNO}_{3}+1 \mathrm{ml} \mathrm{H}_{2} \mathrm{O}_{2}\end{array}$} \\
\hline 2 & 8 & 800 & 4 & 120 & 5 & \\
\hline 3 & 8 & 800 & 8 & 80 & 2 & \multirow{2}{*}{$\begin{array}{l}\text { The solution then allowed } \\
\text { to cool down below } 30^{\circ} \mathrm{C} \\
\text { then } 4 \mathrm{ml} \text { of UP-S Grade } 30 \\
w t \% \mathrm{HCl} \text { was added. }\end{array}$} \\
\hline 4 & 8 & 800 & 4 & 120 & 5 & \\
\hline
\end{tabular}

The digested sample then analysed using Inductively Coupled Plasma - Mass Spectrometry (ICP-MS, Nexion 300x). Multi-elements standard calibration curves were made by diluting and mixing different single element standard reference stock solutions (Sigma-Aldrich).

A morphology study of the milled LIB particles was carried out using an SEM-EDX. The EDX helps in identifying the material being studied. The samples were mounted onto aluminium stage by using conductive carbon tape. The surface of the sample then made conductive by applying a $4 \mathrm{~nm}$ gold layer by using a gold sputtering machine (LEICA EM SCD 500).

\subsection{Data processing and analysis}

Selective crushing has been exploited in the minerals industry where the typical case presents the different distribution of valuable and waste minerals concentrated by particle size. In this study, the milled LIBs were sieved into eight different size fractions of $13200 \mu \mathrm{m}-9500 \mu \mathrm{m}, 9500 \mu \mathrm{m}-6700 \mu \mathrm{m}, 6700 \mu \mathrm{m}-4750 \mu \mathrm{m}, 4750 \mu \mathrm{m}-2360$ $\mu \mathrm{m}, 2360 \mu \mathrm{m}-850 \mu \mathrm{m}, 850 \mu \mathrm{m}-212 \mu \mathrm{m}, 212 \mu \mathrm{m}-38 \mu \mathrm{m}$, and $<38 \mu \mathrm{m}$. The weight percentage at given a size range is then calculated.

The results of sieving should always be plotted graphically to assess their full significance, the most common being that plotting either cumulative undersize or oversize against particle size [32]. The plot of cumulative undersize is a mirror image of cumulative oversize, and therefore, it is not necessary to plot both curves. The plot is carried out using a semi-logarithmic coordinate to avoid finer aperture sizes become congested. In this study, the cumulative undersize is used as a means to interpret the particle size distribution. Samples at a given size range then analysed for aluminium, cobalt and copper content, and the recovery rate of a certain element at a given size range can then be found. 


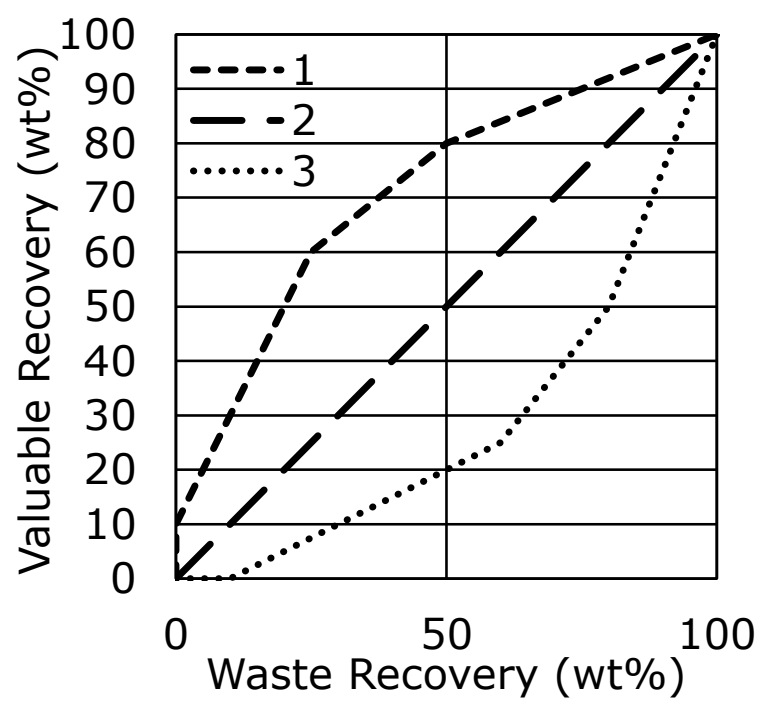

Figure 1 - An example of recovery plot as Fuerstenau upgrading curve with percentage finer; re-drawn from Hesse, Popov [33].

In minerals engineering, selective liberation has been observed by researchers, an example of which is iron ore and lead-zinc ore $[33,34]$. Analysis of selective liberation may be carried out using a Fuerstenau and ore separation degree ( $\eta_{\text {ore }}$ ) diagrams. The Fuerstenau diagram gives meaningful information, whether the valuable material that is being recovered is concentrated in the finer or coarser size region. Figure 1 shows a method for evaluating the effect of selective comminution. This is a Fuerstenau upgrading diagram showing recovery plots of the classified comminution product [35, 36]. The recovery of valuable minerals ( $R v)$ and the waste material $(R w)$ can be plotted in the diagram for various separation cut points $t_{d}$, for either fine or coarse fraction. Figure 1 shows the result for the fine fraction. A linear diagonal line indicates that there is no selectivity in the investigated material (Line 2 in Figure 1). Enrichment of the valuable component in the finer fraction is documented by a recovery curve positioned above the diagonal line (Line 1 in Figure 1). A recovery curve below the diagonal line shows enrichment of valuable component occurs in coarser fraction (Line 3 in Figure 1).

Other than Fuerstenau upgrading diagram, the 胍e diagram gives meaningful information related to the cut point $t_{d}$ that maximise the recovery of valuable material

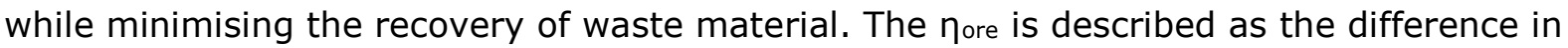
the recovery of valuable and waste material and summarised in Eq. (1).

$$
\eta_{\text {ore }}=R_{v}-R_{w}
$$

When the concentration of valuable minerals depends on the particle size of the product, then $\eta_{\text {ore }}$ changes and is dependent on the separation cut $t_{d}$. Thus, the optimum cut point corresponds to the highest ore separation degree ( $\eta_{\text {ore,max }}$ ). Moreover, the $\eta_{\text {ore }}$ may be regarded as the efficiency of selective liberation. When $R_{v}$ is equal to $100 \%$ and $R w$ is 
$0 \%$ implies $\eta_{\text {ore }}$ of $100 \%$, in other words, all the valuable materials have been recovered below the cut point $t_{d}$ with no contamination from the waste or unwanted material.

The Fuerstenau upgrading diagram and nore are used to assess the selective liberation that occurs when milling spent LIBs. Such that, the liberation of the $\mathrm{LiCoO}_{2}$ laminate (identified by the detection of cobalt), copper and aluminium at different cut point size can then be identified. The compensation effect between $\mathrm{LiCoO}_{21}$ laminate and the copper and aluminium current collectors by increasing cut point will be identified. Moreover, the selective liberation of aluminium towards copper can also be identified. 


\section{Results and discussion}

\subsection{Size-based hierarchy of milled LIBs}

Table 2 - The cumulative undersize semi-logarithmic plot of shredded spent and new lithium-ion battery and the concentration of key material for a given size range.

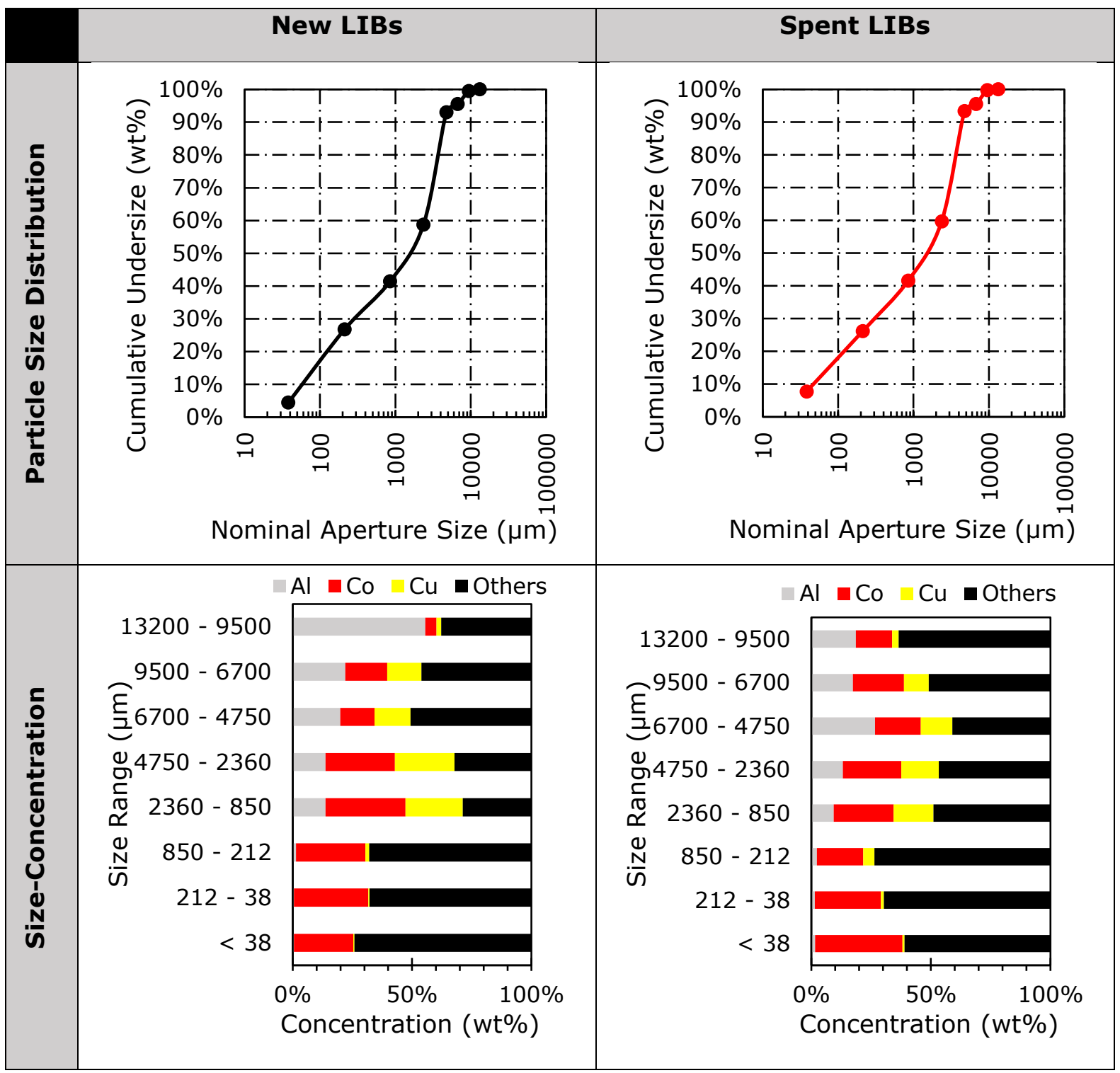

From Table 2, milling spent LIBs in a cutting mill with an $8 \mathrm{~mm}$ grid, resulted in a wide range particle size distribution and the average particle size $\left(d_{50}\right)$ of new and spent LIBs were revealed to be $1600 \mu \mathrm{m}$ and $1552 \mu \mathrm{m}$ respectively. The average particle size of new LIBs is only slightly bigger and does not significantly different to that of spent LIBs. However, it is realized that there is more $<38 \mu \mathrm{m}$ particles in spent LIBs ( $7.7 \mathrm{wt} \%$ ) than in new LIBs (4.4 wt\%).

Comparing the cobalt grade between different size fractions in Table 2 (Spent LIBs), it was found that the size fraction $<38 \mu \mathrm{m}$ has the highest grade of $36.5 \mathrm{wt} \%$ cobalt. The 
size fraction $<38 \mu \mathrm{m}$ also has the lowest contamination of aluminium and copper, which are $1.6 \mathrm{wt} \%$ and $0.8 \mathrm{wt} \%$ respectively. Nonetheless, this size fraction only contributes $7.7 \mathrm{wt} \%$ from the entire feed and equates to $\mathrm{LiCoO}_{2}$ recovery rate of $11.4 \mathrm{wt} \%$.

Compared to that of the new LIBs (Table 2), the $<38 \mu \mathrm{m}$ size fraction contains lower grade of $24.9 \mathrm{wt} \%$ cobalt with lower aluminium and copper contamination of $0.5 \mathrm{wt} \%$ and $0.6 \mathrm{wt} \%$ respectively. In the case of new LIBs, the size fraction of $212 \mu \mathrm{m}-38 \mu \mathrm{m}$ contains the highest grade of $31.2 \mathrm{wt} \%$ cobalt with minimum contamination from aluminium (0.4 wt\%) and copper (0.5 wt\%). Therefore, to make an objective judgement related to whether milling $\mathrm{LIBs}$ does induce selective liberation of $\mathrm{LiCoO}_{2}$ laminate, Fuerstenau upgrading diagram, and nore was plotted. By this way, the interactions between $\mathrm{LiCoO}_{2}$ laminate (cobalt), copper and aluminium can then be studied. Moreover, the comparison between the new and spent LIBs can also be made in order to understand the phenomenon described above.
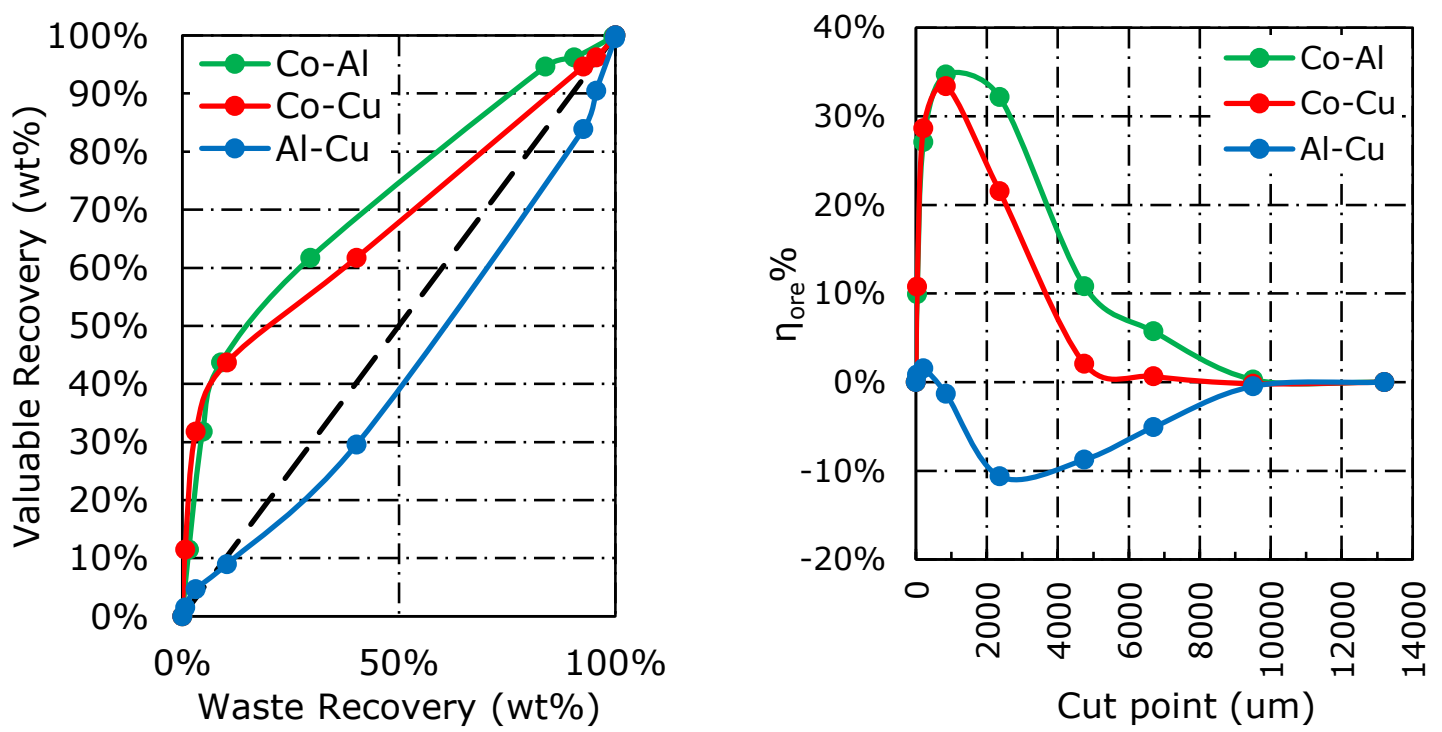

Figure 2 - Fuerstenau upgrading curve (left) and ore separation degree ( $\eta_{\text {ore }}$ ) (right) of the milled spent LIBs.

Figure 2 shows that milling spent LIBs does induce selective liberation of $\mathrm{LiCoO}_{2}$ particles. The recovery of cobalt is greater than the recovery of copper and aluminium in the finer size region. The Fuerstenau upgrading diagram can be broken down into two distinct regions, which are the recovering region and the re-mixing region. In the recovering region, the cobalt recovery increases by increasing the cut point size also accompanied by a minimum increase in copper and aluminium recovery. Further increase in cut point yield higher wt\% recovery of cobalt but the increase is outweighed by the increase in copper as well as aluminium recovery and called the re-mixing region. When there is a point of inflection, the recovering line changes into re-mixing line; it marks the optimum cut point that balances the compensation between valuable material 
recovery and waste material recovery. For both $\mathrm{Co}-\mathrm{Al}$ and $\mathrm{Co}-\mathrm{Cu}$, the transition can be seen at point $850 \mu \mathrm{m}$. Comparing the $\eta_{\text {ore }}$ curves in Figure 2, the cut point $850 \mu \mathrm{m}$ gives the highest efficiency to recover cobalt while minimising the contamination of aluminium and copper (Co-Al $\eta_{\text {ore } \max }=37.8 \%$ and Co-Cu $\eta_{\text {ore, } \max }=33.4 \%$ ). Moreover, a dramatic decrease in Co-Cu $\eta_{\text {ore }}$ is observed when compared to Co-Al $\eta_{o r e}$ above cut point $850 \mu \mathrm{m}$. This indicates that above the cut point $850 \mu \mathrm{m}$, the copper contamination is more dominant than the aluminium contamination.

Inside the cutting chamber, size reduction occurs through shearing and cutting stress [37]. Cutting actions applies a localised force that induces failure of the material right next to the knife edge as a result of shear and tensile stresses. With the assumption that there is no interaction between the active materials assembly and the electrode. The tensile strength of copper (220 MPa) has been reported to be higher than the tensile strength of aluminium (105 MPa - $145 \mathrm{MPa}$ ) [38]. Moreover, copper (2.65 GPa) also has a higher ideal shear strength as compared to aluminium (1.85 GPa) shear strength [39]. In light of these facts, inconsistency was found. By considering the shear and tensile strength of copper and aluminium, it is expected that the aluminium would be more readily liberated in the finer size region. However, the revealed finding seems to contradict this fact. By comparing the interactions of $\mathrm{Co}-\mathrm{Al}$ and $\mathrm{Co}-\mathrm{Cu}$ in the Fuerstenau upgrading curve, there is a trend switch in the recovery and re-mixing region. Where, in the recovery region, increasing the cut point size leads to a higher increase in aluminium recovery rather than copper recovery. Additionally, in the re-mixing region, this trend does not hold true and switch towards more copper being recovered as the cut point become bigger.

To make a better graphical representation, the interaction between aluminium and copper $(\mathrm{Al}-\mathrm{Cu})$ then plotted for Fuerstenau upgrading curve and $\eta_{\text {ore, }}$ in which the aluminium is taken as the valuable component. As it can be seen from Figure 2, the Fuerstenau upgrading curve of $\mathrm{Al}-\mathrm{Cu}$ also shows a switch in trend. Initially, the Fuerstenau upgrading diagram shows recovery of aluminium above the diagonal line prior to approaching cut point $212 \mu \mathrm{m}$. However, as the cut point size increased, the remixing line lies below the diagonal line. Similarly, for the nore curve, the efficiency is only positive in the region of $<212 \mu \mathrm{m}$ and the $\eta_{\text {ore }}$ become a negative value onwards. The Пore negative value implies that the recovery rate of waste material (copper) is higher than that of the valuable material (aluminium) as the cut point become bigger. With the highest $\eta_{\text {ore }}$ for $\mathrm{Al}-\mathrm{Cu}$ is $1.6 \%$ with cut point $212 \mu \mathrm{m}$. Moreover, the cut point $2360 \mu \mathrm{m}$ gives the highest $\eta_{\text {ore }}$ of copper towards aluminium.

From the findings described above, indicates that the interaction between the active materials assembly towards the current collector cannot be negated. This also 
demonstrate that $\mathrm{LiCoO}_{2}-\mathrm{PVDF}-\mathrm{Al}$ is more resilient than that of $\mathrm{C}_{6}-\mathrm{PVDF}-\mathrm{Cu}$. The mechanical strength of current collectors and the adhesive strength of the binder are dependent upon the number of discharging and charging cycles the battery undergone. The repetitive cycle of charging and discharging the active materials undergoes causes repeated expansion and shrinkage due to the periodic intercalation and de-intercalation of lithium ions [40-42]. The repetitive deformation then induces mechanical ageing to the current collectors [43]. Furthermore, degradation of PVDF adhesiveness on to the current collector has also been reported to weaken, causing contact loss of active material $[24,25]$. Therefore, a comparison to the new milled LIBs was made to observe the difference in selective liberation in new and spent LIBs. The comparison of selective liberation of new and spent LIBs are summarised in Table 3. 
Table 3 - Comparison of Fuerstenau upgrading curve and ore separation degree ( $\eta_{\text {ore }}$ ) of Co-Al, Co-Cu and Al-Cu for new and spent lithium-ion battery.

\begin{tabular}{|c|c|c|}
\hline & Fuerstenau Upgrading Curve & Ore Separation Degree ( \\
\hline & 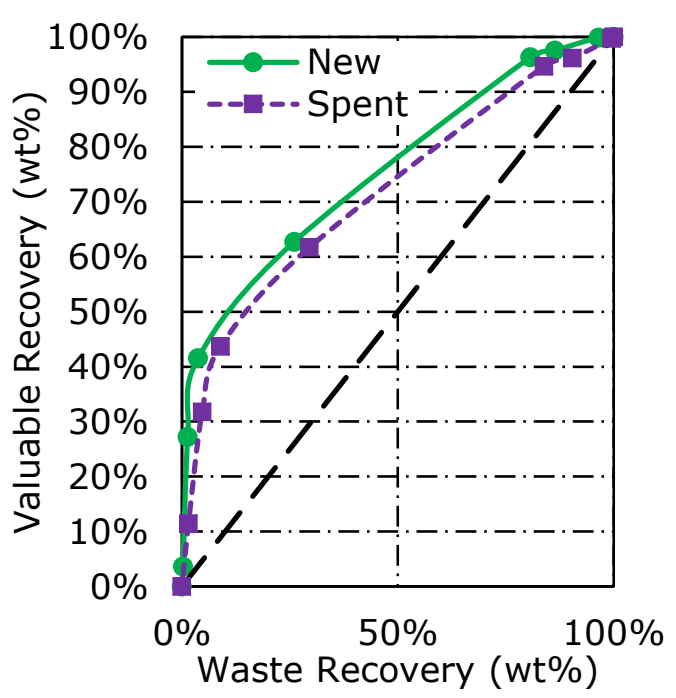 & 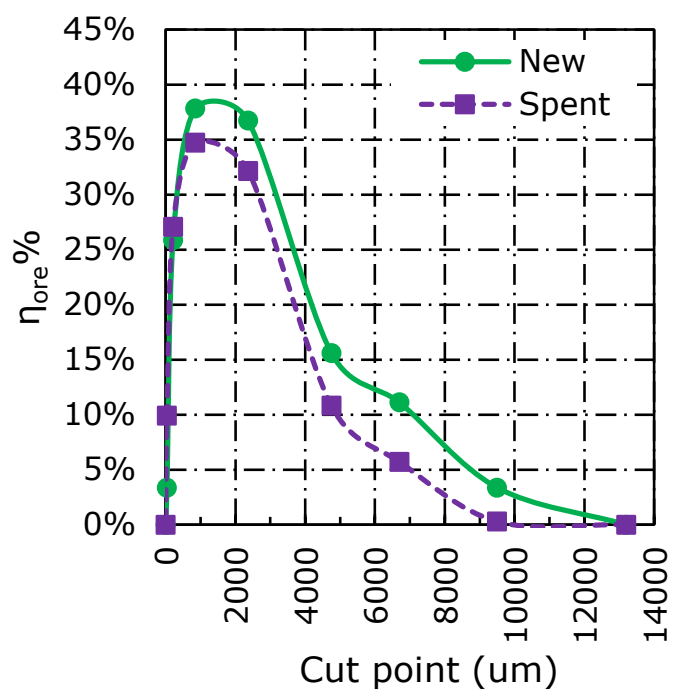 \\
\hline $\begin{array}{l}\text { Uె } \\
1 \\
0\end{array}$ & 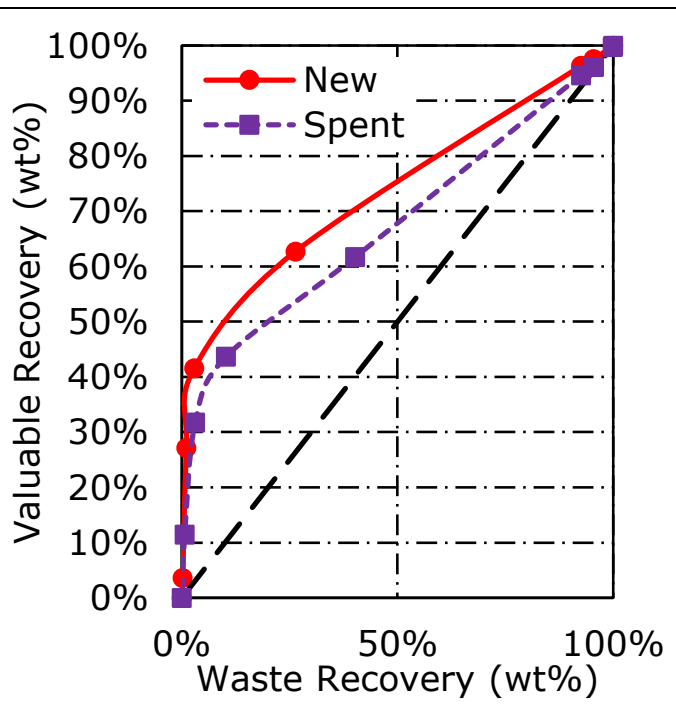 & 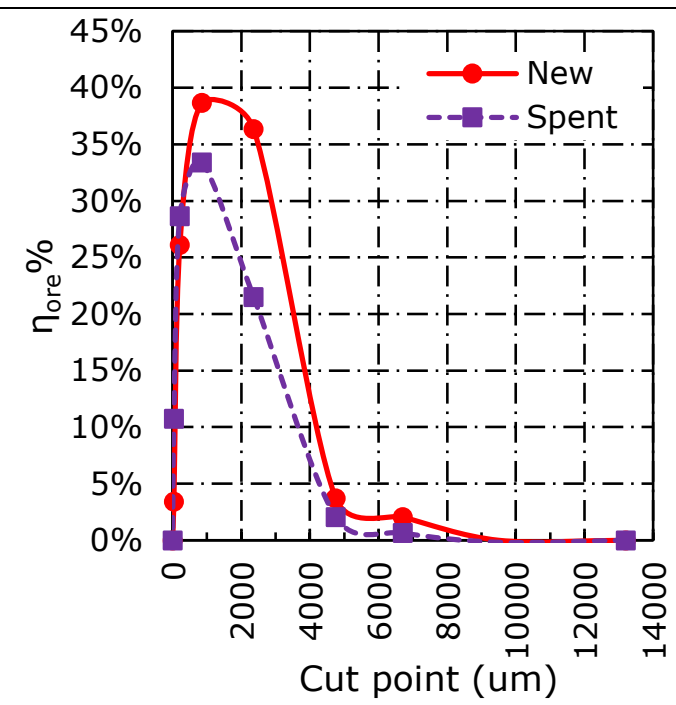 \\
\hline $\begin{array}{l}\vec{U} \\
\frac{1}{4}\end{array}$ & 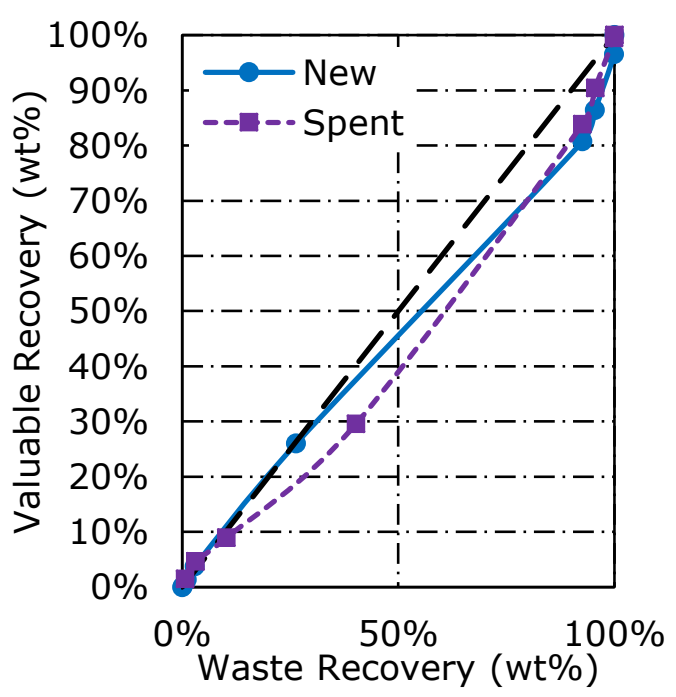 & 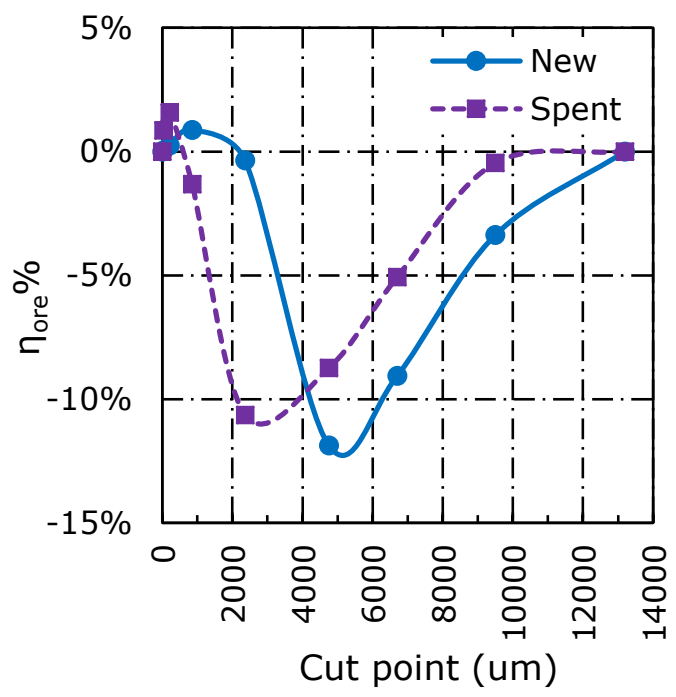 \\
\hline
\end{tabular}


From Table 3, it can be deduced that the milling of new LIBs does induce selective liberation of positive electrode active materials in the finer size region. Additionally, the

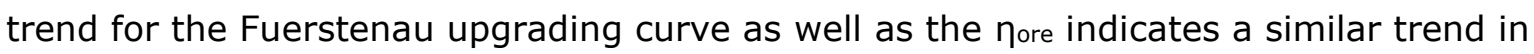
selective liberation of positive electrode active materials. The cut point of $850 \mu \mathrm{m}$ applies as the optimum cut point to concentrate positive electrode active material while minimising the contamination from copper and aluminium.

Comparing the new and spent LIBs, in Table 3, the Co-Al and Co-Cu curves indicate better separation efficiency for the new LIBs. From Table 3 ( $\eta_{\text {ore }}$ ), after Co-Al and Co-Cu curves approach $\eta_{\text {ore,max, }}$ the efficiency quickly decreases as the cut point became bigger for both LIBs. Furthermore, the decrease in efficiency is more apparent for the Co-Cu nore curve, compared to the Co-Al $\eta_{\text {ore }}$ curve for spent LIBs. This is thought to occur due to the difference in adhesive strength of PVDF binder with the copper and aluminium current collector. The active materials on the copper current collector (graphite) and on the aluminium current collector $\left(\mathrm{LiCOO}_{2}\right)$ are held together by the PVDF binder to form a composite. The cushioning of copper and aluminium current collector by its respective active materials may help in preventing breakage during mechanical liberation. It has been reported that the adhesive strength of PVDF to copper is $285.6 \mathrm{kPa}$ in a new LIB battery is lower than that of aluminium which is $841.2 \mathrm{kPa}$ [26]. Therefore, in the case of new LIBs, the lower PVDF adhesive strength towards copper current collector as compared to the aluminium current collector counterpart, may help explain the higher rate of decrease in efficiency as the $\eta_{\text {ore }}$ curve approaching $\eta_{\text {ore, max }}$ in the Co-Cu $\eta_{\text {ore }}$ curve as compared to the Co-Al nore curve.

As the LIBs are used in multiple cycles, the adhesive strength of PVDF onto copper and aluminium current collectors decreases to $55.5 \mathrm{kPa}$ and $132.8 \mathrm{kPa}$ respectively, after 200 cycles [26]. Moreover, the elastic modulus of copper further decreases as the battery is cycled a reduction of $78 \%-80 \%$ has been reported [26]. For spent LIBs, the degradation of PVDF adhesive strength and the elastic modulus of the copper current collector causes more copper to be liberated in the finer size region. The aluminium current collector counterpart also undergoes localised corrosion and produces perforation [44]. This corrosion induced perforation potentially weakened the mechanical properties of the aluminium foil in spent LIBs. Thus, in the case of spent LIBs, the copper and aluminium current collectors are more contaminating in the finer size fraction $(<850 \mu \mathrm{m})$ and therefore translated as a lower overall nore,max value.

From Table 3, the Fuerstenau upgrading diagram shows an Al-Cu curve of spent LIBs below the diagonal line in the size range of $>212 \mu \mathrm{m}$. Whereas, the new LIBs shows a recovery curve below the diagonal line in the size range of $>2360 \mu \mathrm{m}$. Moreover, the $\eta-$ ore curves reveal that the cut point required to exploit this selectivity increases from 2360 
$\mu \mathrm{m}\left(\eta_{\text {ore }, \max }=10.6 \%\right)$ to $4750 \mu \mathrm{m}\left(\eta_{\text {ore }} \max =11.9 \%\right)$. It is also important to point out that the Al-Cu nore curve predominant size is different for spent and new LIBs. The new LIBs has an Al-Cu nore curve that is more dominant towards the larger size region. Whereas, the nore curve of spent LIBs has shifted towards the finer size region. The change in predominant size towards the finer size region, in milling spent LIBs, indicates the copper and aluminium favour further breakage into the smaller size region. Therefore, the better mechanical properties of positive and negative electrode in new LIBS synergistically translates to a bigger cut point as compared to spent LIBs. While the increase in $\eta_{\text {ore, } \max }$ is caused by the lower recovery of copper towards aluminium in size range of $<2360 \mu \mathrm{m}$.

Thus, to investigate this phenomenon, a morphology study of classified milled product is done by using SEM-EDX. 


\subsection{Particles morphology of milled LIBs}

3.1

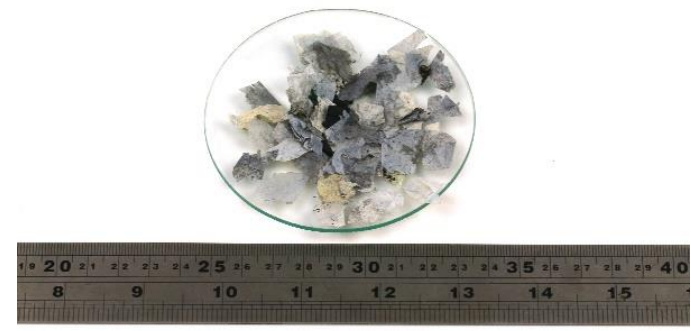

3.2

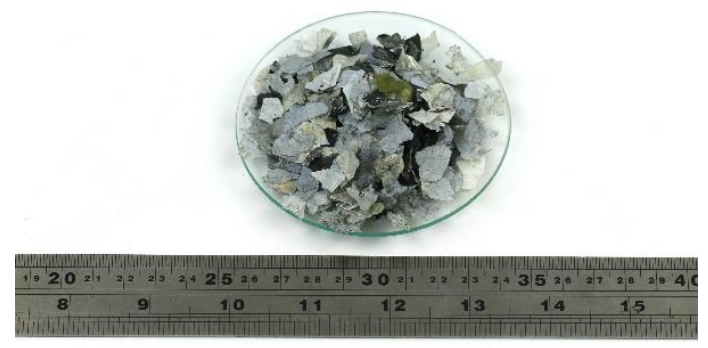

3.3

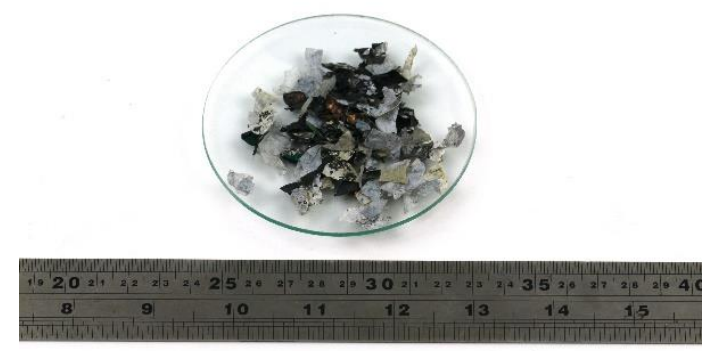

3.4

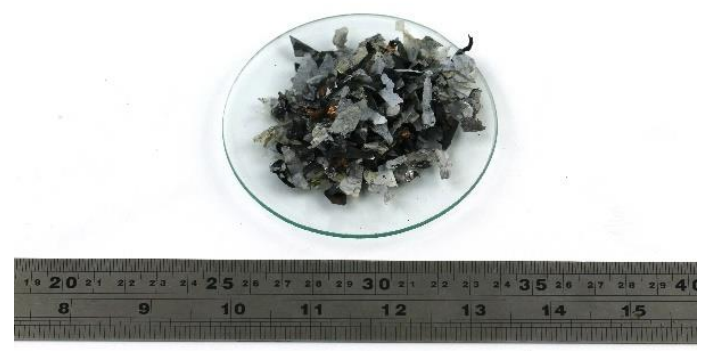

3.5

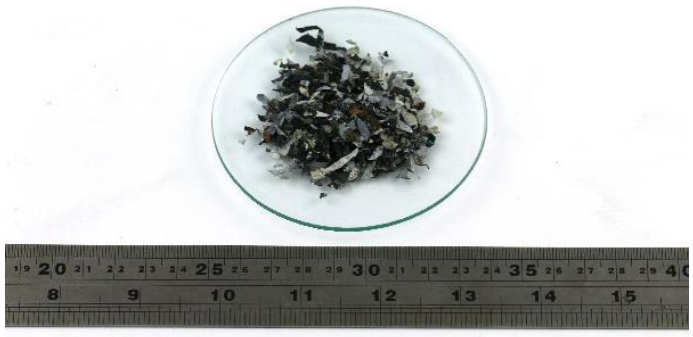

3.6

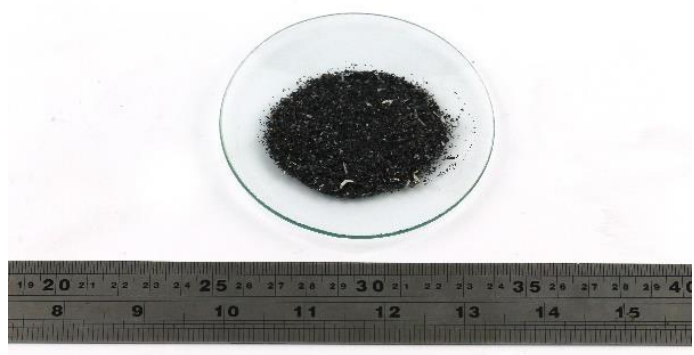

3.7

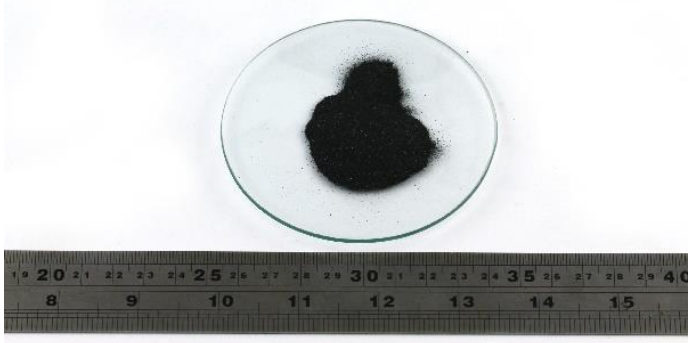

3.8

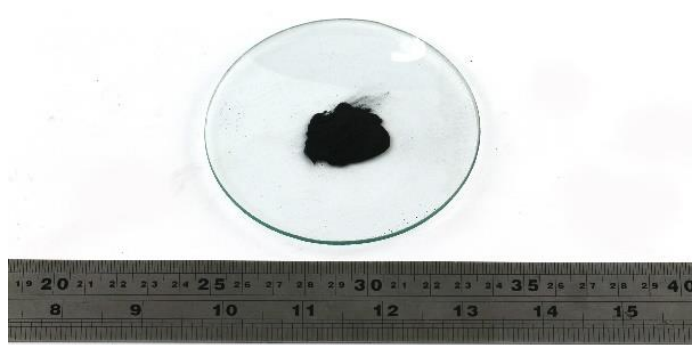

Figure 3 - Classified milled spent LIBs; 3.1)13200 $\mu \mathrm{m}-9500 \mu \mathrm{m}, 3.2) 9500 \mu \mathrm{m}-6700 \mu \mathrm{m}$, 3.3) $6700 \mu \mathrm{m}-4750 \mu \mathrm{m}, 3.4) 4750 \mu \mathrm{m}-2360 \mu \mathrm{m}, 3.5) 2360 \mu \mathrm{m}-850 \mu \mathrm{m}, 3.6) 850 \mu \mathrm{m}-212 \mu \mathrm{m}$, 3.7) $212 \mu \mathrm{m}-38 \mu \mathrm{m}, 3.8)<38 \mu \mathrm{m}$. 
Figure 3 presents the classified product from milled spent LIBs. The polymeric materials from the separator and the battery chassis are mainly found in the bigger size fraction $(>850 \mu \mathrm{m})$. Through visual inspection, separator in the size region of $<850 \mu \mathrm{m}$ was found to be minimum. Observation by using SEM for different size fraction then made. This morphological analysis aims to understand the characteristics of active materials for different size fraction. Samples were mounted to aluminium stage with adhesive carbon tape. The size fraction of $>4750 \mu \mathrm{m}$ was not analysed and based on visual inspection; it is assumed to be the same as the size fraction $4750 \mu \mathrm{m}-2360 \mu \mathrm{m}$. This is thought not to bias the results for the size fraction of $>4750 \mu \mathrm{m}$ only holds less than $7 \mathrm{wt} \%$. The positive electrodes, negative electrodes, and separators were manually collected by using a tweezer for size fraction $4750 \mu \mathrm{m}-2360 \mu \mathrm{m}$ and $2360 \mu \mathrm{m}-850 \mu \mathrm{m}$. Whereas, Size fraction $850 \mu \mathrm{m}-212 \mu \mathrm{m}, 212 \mu \mathrm{m}-38 \mu \mathrm{m}$ and $<38 \mu \mathrm{m}$ were directly mounted onto the adhesive carbon tape. The same preparation also carried out for the milled classified new LIBs. Gold sputtering then carried out at $4 \mathrm{~nm}$ thickness to make the sample surface conductive. 

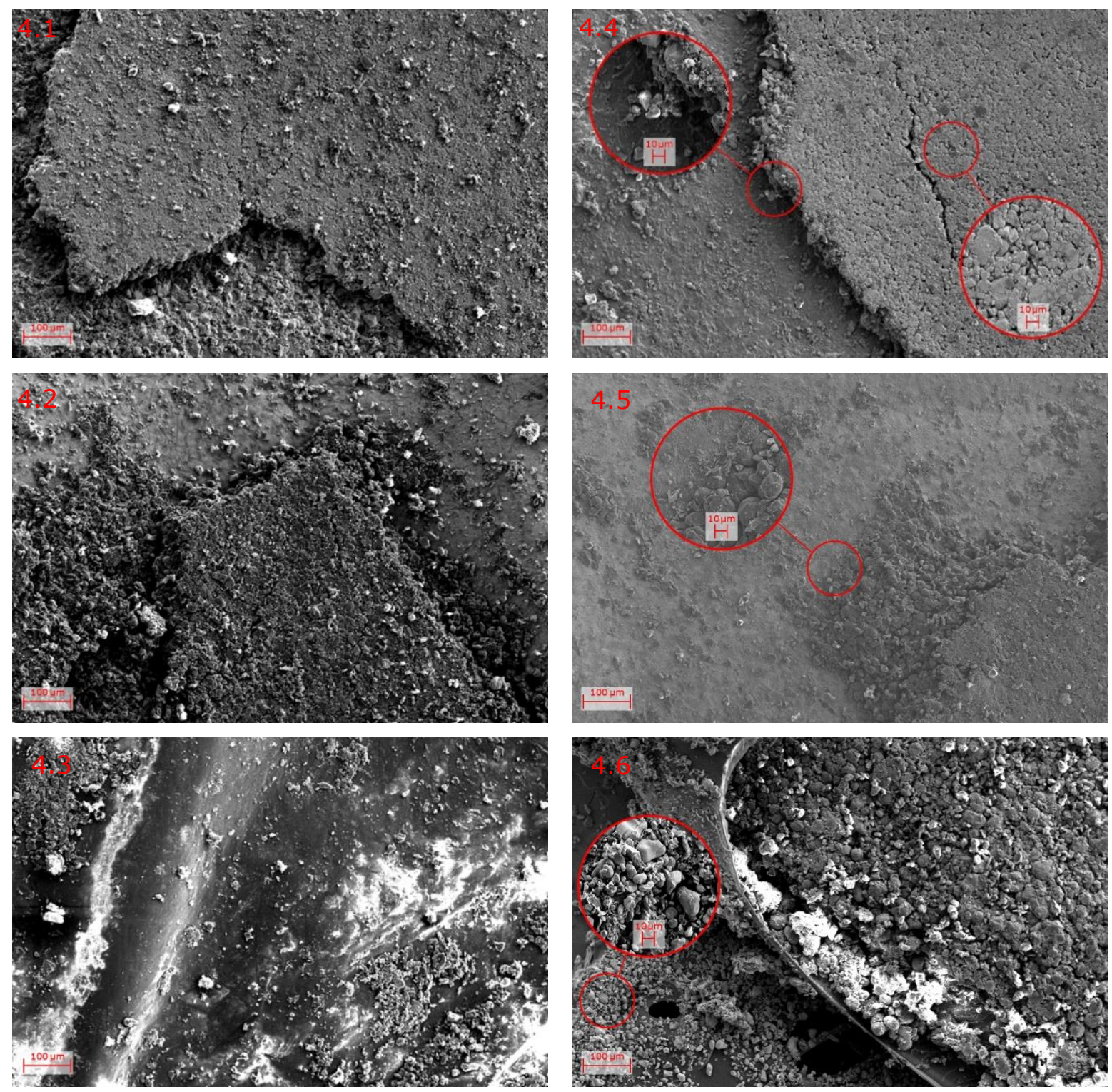

Figure 4 - SEM image of size fraction $4750 \mu \mathrm{m}-2360 \mu \mathrm{m}$; New LIBs: 4.1 Positive electrode, 4.2 Negative electrode, 4.3 Separator; Spent LIBs: 4.4 Positive electrode, 4.5 Negative electrode, 4.6 Separator

From Figure 4, it was discovered that both positive and negative electrode active materials are contaminating the surface of the current collector. Figure 4 also demonstrates that there are no difference in terms of morphology for the new and spent LIBs. From Figure 4.1 and 4.4, there is a partial detachment of $\mathrm{LiCoO}_{2}$ laminate from the aluminium current collector. The $\mathrm{LiCoO}_{2}$ that are still attached to the current collector is still firmly held by the binder. Moreover, the preliminary liberation induces the detachment of positive electrode active materials from its current collector in the form of a big package, indicated by the crack and the clear transition between the side that has $\mathrm{LiCOO}_{2}$ lamination partially removed and intact (Figure 4.1 and 4.4). Moreover, the side that has already lost many of its active materials is still contaminated with a thin layer of $\mathrm{LiCoO}_{2}$ lamination. 
Similar observation also made with the negative electrode that still have graphite lamination partially intact (Figure 4.2 and 4.5 ). However, there is a transition region between the side that has graphite lamination that are partially removed and intact. This indicates that graphite-PVDF-graphite interaction is relatively weaker compared to $\mathrm{LiCOO}_{2}$-PVDF-LiCoO 2 interaction.

The separators collected from the size fraction $4750 \mu \mathrm{m}-2360 \mu \mathrm{m}$ are contaminated with both $\mathrm{LiCOO}_{2}$ and Graphite laminates. This may have been due to the compression action in the cutting mill. However, the attachment of the active materials is weak. By manually folding the separator using a tweezer, the powders attached to the separator were transferred onto the carbon tape (Figure 4.3). This indicates that the attachment of positive and negative electrode active materials onto the separator is relatively weak, but sieving alone does not help in detaching the active materials cast on the separator. The new LIBs also shows the same characteristics (Figure 4.6).

For the size fraction $>2360 \mu \mathrm{m}$, the particles in this region contain positive and negative electrodes that have undergone size reduction and accompanied by the partial liberation of active materials. The active materials laminate are still firmly attached and contaminating the surface of the electrodes. The analysis also shows that the graphite laminate is more liberated compared to the $\mathrm{LiCoO}_{2}$ laminate. Some active materials laminate are also found to be attached on to the separator, and as a result, it may reduce the recovery of $\mathrm{LiCoO}_{2}$ during size-based separation. 

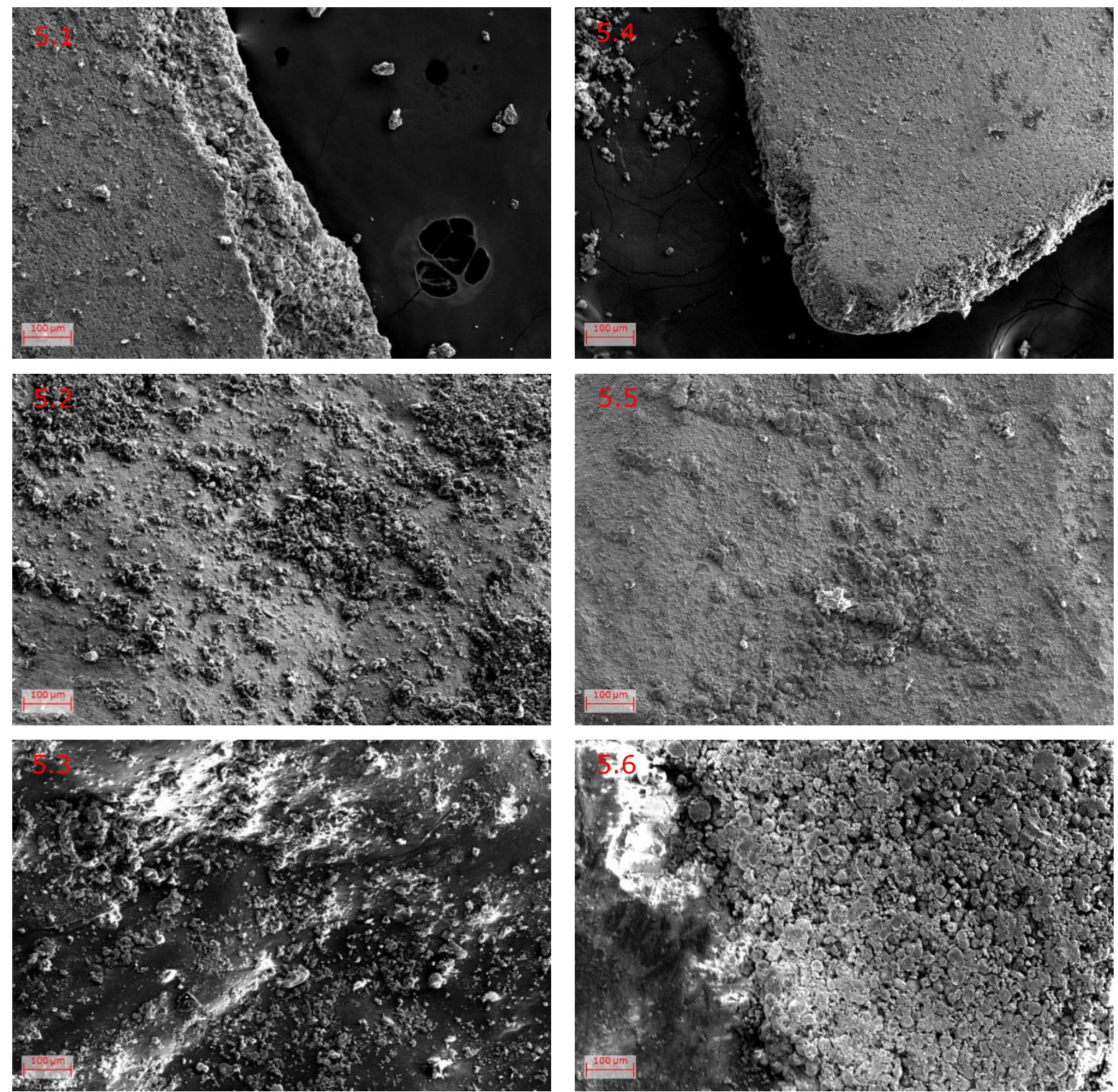

Figure 5 - SEM image of size fraction $2360 \mu \mathrm{m}-850 \mu \mathrm{m}$; New LIBs: 5.1 Positive electrode, 5.2 Negative electrode, 5.3 Separator; Spent LIBs: 5.4 Positive electrode, 5.5 Negative electrode, 5.6 Separator.

Figure 5, which is the $2360 \mu \mathrm{m}-850 \mu \mathrm{m}$ reveals that the $\mathrm{LiCoO}_{2}$ and graphite lamination are still contaminating the surface of the current collectors as well as the separator. Figure 5 also indicates no morphological difference between the new and spent LIBs. From Figure 5.1 and 5.4, $\mathrm{LiCoO}_{2}$ particles in the size fraction of $2360 \mu \mathrm{m}-$ $850 \mu \mathrm{m}$ are firmly held by the binder and laminating the aluminium current collector. This phenomenon indicates that the preliminary liberation also induces size reduction with the minimum liberation of $\mathrm{LiCOO}_{2}$ lamination from its aluminium current collector (i.e. the aluminium and $\mathrm{LiCoO}_{2}$ lamination breaks in unity). From Figure 5.2 and 5.5, the copper current collector still has graphite lamination. However, it is cleaner when compared to the positive electrode. This also indicates that the graphite lamination is more readily liberated as compared to $\mathrm{LiCoO}_{2}$ lamination that remain fixed. From Figure 
5.3 and 5.6, the separator is contaminated with $\mathrm{LiCoO}_{2}$ and graphite laminates. The attachment of $\mathrm{LiCoO}_{2}$ and graphite laminates to the separator is relatively weak, as discussed in the size range $4750 \mu \mathrm{m}-2360 \mu \mathrm{m}$.

From the size fraction $2360 \mu \mathrm{m}-850 \mu \mathrm{m}$, it is shown that this region contains a positive electrode that has undergone a reduction in size with the minimum liberation of $\mathrm{LiCoO}_{2}$ laminate. However, the negative electrode is relatively clean from graphite laminate. Similarly, with the finding from size range $4750 \mu \mathrm{m}-2360 \mu \mathrm{m}$, the graphite laminate is more readily liberated than the $\mathrm{LiCoO}_{2}$ laminate from its current collector. Active materials laminate also found to be contaminating the separator that also hinders sizebased separation.
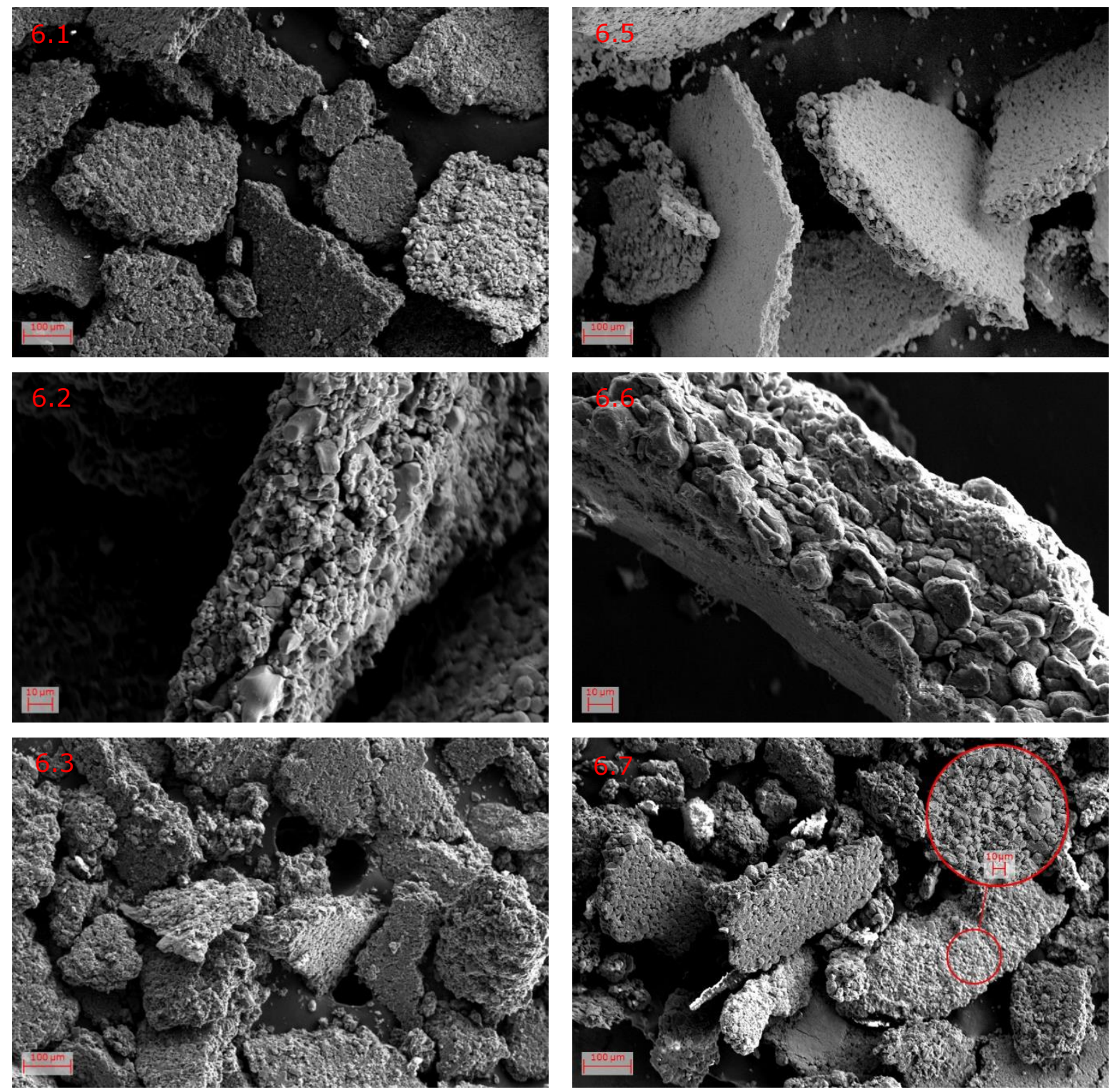

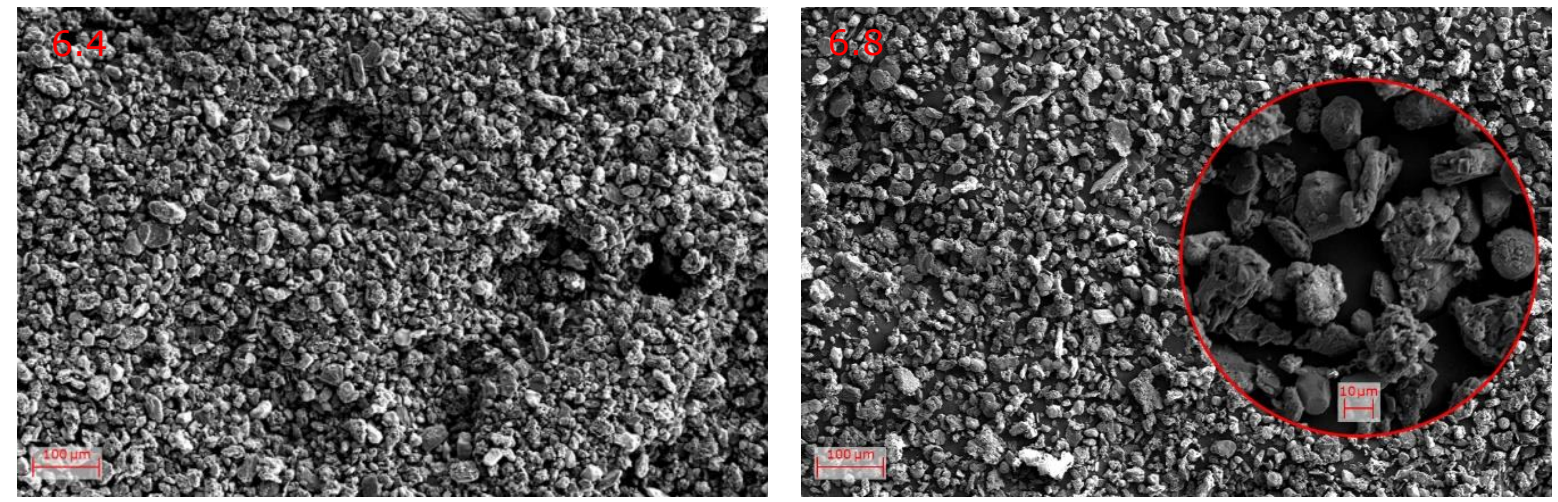

Figure 6 - SEM image of size fraction < $850 \mu \mathrm{m}$; New LIBs: 6.1 Powder from size fraction $850 \mu \mathrm{m}-212 \mu \mathrm{m}, 6.2$ Zoomed $\mathrm{LiCoO}_{2}$-PVDF aggregate from size fraction 850 $\mu \mathrm{m}-212 \mu \mathrm{m}$ identified by EDX, 6.3 Powder from size fraction $212 \mu \mathrm{m}-38 \mu \mathrm{m}, 6.4$ Powder from size fraction < $38 \mu \mathrm{m}$; Spent LIBs: 6.5 Powder from size fraction $850 \mu \mathrm{m}-$ $212 \mu \mathrm{m}, 6.6$ Zoomed $\mathrm{LiCoO}_{2}$-PVDF aggregate from size fraction $850 \mu \mathrm{m}-212 \mu \mathrm{m}$

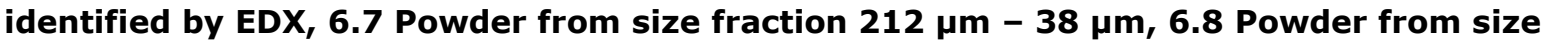
fraction $<38 \mu \mathrm{m}$.

Figure 6 presents the morphology of new and spent LIBs in size range of $<850 \mu \mathrm{m}$, and it can be concluded that there is no significant difference between the two. From Figure 6.1 and 6.5, the size fraction $850 \mu \mathrm{m}-212 \mu \mathrm{m}$ contains initially graphite and $\mathrm{LiCoO}_{2}$ laminate that have been detached from its current collector and only held together by the binder. Moreover, there are substantial $\mathrm{LiCoO}_{2}$ fine particles aggregates (Figure 6.2 and 6.6) that are covered by the binder. Similar observation also made for the size range of $212 \mu \mathrm{m}-38 \mu \mathrm{m}$ (Figure 6.3 and 6.7) as well as size range of $<38 \mu \mathrm{m}$ (Figure 6.4 and 6.8 ). With the only difference being the size of the aggregates, where the size fraction $<38 \mu \mathrm{m}$ shows the least aggregation between particles. Thus, the size fraction of $<850 \mu \mathrm{m}$ may be classified as the size fraction that concentrates detached $\mathrm{LiCoO}_{2}$ and graphite laminate but is still held together by the PVDF binder.

The surface morphology study allows the identification of the breakage mechanism of LIBs during mechanical liberation. The combination of size-based hierarchy and morphology study can be used to understand the impact of PVDF adhesiveness towards the current collector breakage in mechanical liberation by comparing the new and spent LIBs and further discussed. 


\subsection{The concurrence of size-based hierarchy and its particle morphology}

From the observation above, the new and spent LIBs does not exhibit a significant difference in terms of morphological characteristics. From the morphological analysis, a distinct property is observed above the cut point $850 \mu \mathrm{m}$. The copper foils are cleaner compared to the aluminium foils due to graphite laminate are more readily liberated as compared to $\mathrm{LiCoO}_{2}$ laminate. The positive and negative electrode active materials show similar morphology behaviour below the cut point of $850 \mu \mathrm{m}$. Moreover, the separator is also contaminated by positive and negative electrode active materials.

From the morphological study that has been carried out using SEM, the liberated LIBS can be classified into four major categories based on the attachment of active materials onto the current collector and the size of the active materials detached. The bigger size fractions with active materials laminate on to it are categorised as Category 1 and Category 2 . While the detached active materials that are still aggregated and held together by the binder are categorised as Category 3 and Category 4 . The characteristics of different particles in different size fraction are summarised in Table 4.

In the case of spent LIBs, the stronger attachment of $\mathrm{LiCoO}_{2}$ laminate on to the aluminium foil compared to graphite laminate on to the copper foil may help in explaining the change of trend in the re-mixing line of Fuerstenau upgrading diagram discussed in the previous section. The positive electrode found in the size region of 2360 $\mu \mathrm{m}-850 \mu \mathrm{m}$ were aluminium foils covered with $\mathrm{LiCoO}_{2}$ laminate. The negative electrode counterpart has a minimum graphite lamination. Therefore, the $\mathrm{LiCoO}_{2}$ lamination prevents the aluminium from breaking even further. While the the weaker graphite lamination on to the copper current collector have minimised this benefit and therefore concentrated at smaller size fraction. This can be seen from the size-based recovery rate in Table 4. The size-based recovery rate explains the recovery rate of a certain recoverable given it is isolated in a given size range and the sum of recovery rate of a certain recoverable for the entire size range is unity. 
Table 4 - Characterisation of classified LIBs powder

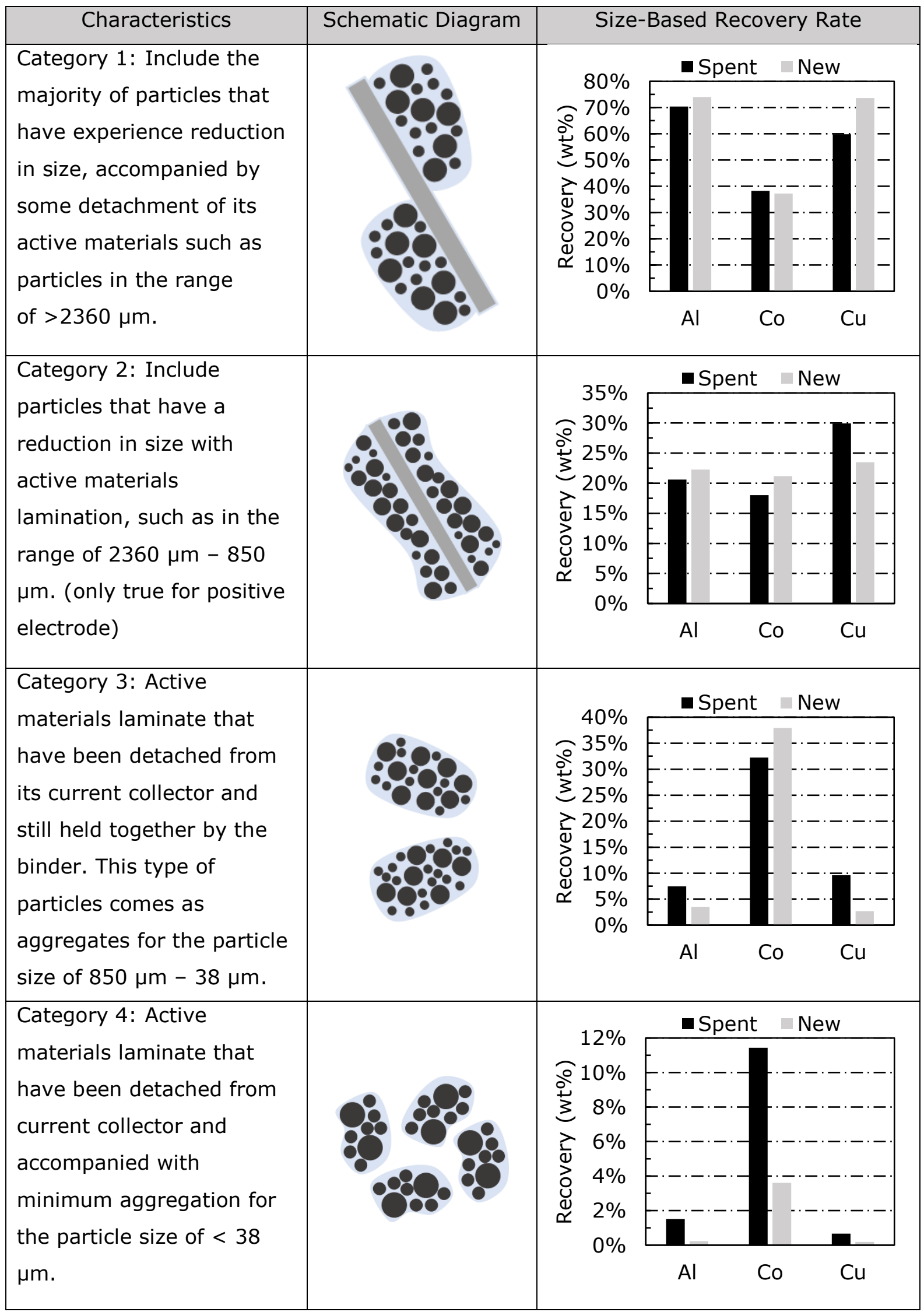


From Table 4, in the case of spent LIBs, when the size fraction above $2360 \mu \mathrm{m}$ is isolated, the recovery rate of aluminium is higher than that of copper. Moreover, the recovery rate of copper is higher than aluminium in size range of $2360 \mu \mathrm{m}$ to $212 \mu \mathrm{m}$ and became aluminium dominant in the size fraction $<212 \mu \mathrm{m}$. Although copper has better ideal mechanical properties and the perforation that occurs on the aluminium current collector, the stronger attachment of $\mathrm{LiCoO}_{2}$ laminate on to aluminium current collector seems to improve its overall mechanical properties and preventing it from breaking during milling. Instead, the shear and tensile stresses induced by the cutting mill dislodged the $\mathrm{LiCoO}_{2}$ laminate in the form of big package forming Category 1 particles and the dislodged $\mathrm{LiCoO}_{2}$ package concentrated in the size region of $<850 \mu \mathrm{m}$ (Category 3 and 4 ). However, when the stress-strain induced by the cutting mill does not dislodge the materials on its surface. Instead, it reduces the particle size while maintaining the active materials intact, covering the whole surface area resulting in Category 2 particles. On the other hand, there may not be a tangible benefit towards the mechanical properties for copper current collector due to weak bonding between graphite laminate on to the copper current collector and combined with the reduction in elastic modulus of copper current collector as the battery is cycled, causing the copper to be selectively liberated in the finer region when compared to aluminium.

As a baseline, comparison to the milled new LIBs was carried out. From Table 4, it can be seen that the new LIBs have minimum contamination from copper and aluminium in the size region of $<850 \mu \mathrm{m}$. The better mechanical properties of the current collector and attachment of PVDF binder translates to lower contamination of copper and aluminium in the finer size region. A large difference is observed when comparing the copper recovery in the size region of $>2360 \mu \mathrm{m}$ (Category 1 ) for the new and spent LIBs. The milled new LIBs showed a recovery rate of $73.6 \mathrm{wt} \%$ copper, whereas the spent LIBs showed a recovery rate of only $59.8 \mathrm{wt} \%$ copper. The milled new LIBs produces more Category 1 copper particles. This indicates the significance of the graphite lamination strength in preventing the breakage of the copper current collector. Moreover, the better mechanical properties of the copper current collector in the new LIBs inhibits the breakage of copper particles with minimum active materials attachment $(2360 \mu \mathrm{m}-850 \mu \mathrm{m})$ into fine particles that contaminates the finer size region $(<850$ $\mu \mathrm{m})$.

Similar interpretation also made with the aluminium particles, in which in the case of new LIBs is less contaminating in the finer size region. Instead, an increase in the recovery of aluminium in the Category 1 and Category 2 particles are observed. The better mechanical properties of the $\mathrm{LiCoO}_{2}$ lamination also prevent the breakage of Category 3 particles into Category 4 particles during mechanical liberation. 


\section{Conclusion}

This article presents a systematic experimental study aimed at understanding the selective liberation of positive electrode active material during milling. From the analysis that has been carried out, the liberation is indeed a selective phenomenon with the optimum cut point of $850 \mu \mathrm{m}$. In the size fraction $<850 \mu \mathrm{m}$, the recovery for spent LIBs is $43.7 \mathrm{wt} \%$ of $\mathrm{LiCoO}_{2}$ with a minimum recovery of aluminium and copper (8.8 wt\% and $10.3 \mathrm{wt} \%$ ) from the feed. However, more than $50 \mathrm{wt} \%$ of $\mathrm{LiCoO}_{2}$ is found in the size region of $>850 \mu \mathrm{m}$, and it contains a substantial amount of aluminium and copper (91.2 wt $\%$ and 89.7 wt\%) from the feed and are not suitable to be treated with leaching.

Milling spent LIBs induces selective liberation of $\mathrm{LiCoO}_{2}$ laminate. From the morphological analysis, $\mathrm{LiCoO}_{2}$ laminate have a stronger attachment to its current collector than the graphite laminate counterparts. From the morphological analysis done, a significant difference between the positive and negative current collector's surface can be seen in the size fraction of $2360 \mu \mathrm{m}-850 \mu \mathrm{m}$ where the negative electrodes are cleaner compared to the positive electrode. The contradiction between copper and aluminium recovery rate towards $\mathrm{LiCoO}_{2}$ recovery rate in the re-mixing line of Fuerstenau upgrading curve may be explained by the stronger $\mathrm{LiCoO}_{2}$ lamination to the aluminium foil as compared to graphite lamination to copper. Other than the positive and negative electrode, some of the $\mathrm{LiCoO}_{2}$ laminate was adhering on to the separator after liberation due to the compression action of the cutting mill. This also reduces the recovery rate of liberated $\mathrm{LiCoO}_{2}$ in smaller size fraction.

The comparison between new and spent LIBs was made. A distinct difference was observed for the interaction of copper towards cobalt and aluminium. Better separation efficiency of $\mathrm{LiCOO}_{2}$ particles is observed in the selective liberation of new LIBs. The better mechanical properties of current collectors and the adhesiveness of the binder in the new LIBs have made the finer size region to be less contaminated by the copper and aluminium. The effect of PVDF binder in preventing the breakage of copper current collector can be observed by the higher occurrence of copper in Category 1 particles in new LIBs than in spent LIBs. The better mechanical properties of new LIBs prevents the breakage of current collectors that contaminates the fine size region $(<850 \mu \mathrm{m})$.

The mechanism of the selective liberation of $\mathrm{LiCoO}_{2}$ laminate has been proposed. During milling, two possible outcomes may arise. Either $\mathrm{LiCoO}_{2}$ laminate are dislodged and released in the form of $\mathrm{LiCOO}_{2}$-PVDF aggregates that are concentrated in the size fraction of $<850 \mu \mathrm{m}$ or size reduction occurs while maintaining its attachment to the current collector. However, the size of the $\mathrm{LiCoO}_{2}-\mathrm{PVDF}$ aggregates that are dislodged is still far from the actual size of $\mathrm{LiCOO}_{2}$ particles as found in spent LIBs. Therefore, the cut point 
proposed $(850 \mu \mathrm{m})$ is much greater than the actual size of $\mathrm{LiCoO}_{2}$ particles found in spent LIBs (ca. $1.50 \mu \mathrm{m}-7.80 \mu \mathrm{m}[23]$ ).

\section{Acknowledgement}

The authors are grateful for the support from New Material Institute, The University of Nottingham Ningbo China.

This work is financially supported by the Industrial Technology Innovation and Industrialization of Science and Technology Project (2014A35001-2), Ningbo Natural Science Foundation of Ningbo Science and Technology Bureau (2017A610136), National Natural Science Foundation of China (no. 71901194), and Natural Science Foundation of Zhejiang Province, China (no. LY19G010009), Chinese Science and Technology Support Plan Project (2015BAF04B01-2), and Green Manufacturing System Integration Project 2016 of Chinese Ministry of Industry and Information.

\section{References}

1. Blomgren, G.E., The Development and Future of Lithium Ion Batteries. Journal of The Electrochemical Society, 2017. 164(1): p. A5019-A5025.

2. Winslow, K.M., S.J. Laux, and T.G. Townsend, A review on the growing concern and potential management strategies of waste lithium-ion batteries. Resources, Conservation and Recycling, 2018. 129: p. 263-277.

3. Moradi, B. and G.G. Botte, Recycling of graphite anodes for the next generation of lithium ion batteries. Journal of Applied Electrochemistry, 2016. 46(2): p. 123148.

4. Zeng, X., J. Li, and N. Singh, Recycling of Spent Lithium-Ion Battery: A Critical Review. Critical Reviews in Environmental Science and Technology, 2014. 44(10): p. 1129-1165.

5. Gu, F., et al., An investigation of the current status of recycling spent lithium-ion batteries from consumer electronics in China. Journal of Cleaner Production, 2017. 161: p. 765-780.

6. Gardiner, J. The rise of electric cars could leave us with a big battery waste problem. 2017 [cited 201710 November]; Available from: https://www.theguardian.com/sustainable-business/2017/aug/10/electric-carsbig-battery-waste-problem-lithium-recycling.

7. Prieto-Sandoval, V., C. Jaca, and M. Ormazabal, Towards a consensus on the circular economy. Journal of Cleaner Production, 2017.

8. Swain, B., Recovery and recycling of lithium: A review. Separation and Purification Technology, 2017. 172: p. 388-403.

9. $\quad$ Pillot, C. Li-ion battery material market review and forecast 2012-2025. in 3rd Israeli Power Sources Conference. 2013. Hertzlia (Israel).

10. Huang, B., et al., Recycling of lithium-ion batteries: Recent advances and perspectives. Journal of Power Sources, 2018. 399: p. 274-286.

11. Chen, Y., et al., Thermal treatment and ammoniacal leaching for the recovery of valuable metals from spent lithium-ion batteries. Waste Manag, 2018. 75: p. 469-476.

12. Ojanen, S., et al., Challenging the concept of electrochemical discharge using salt solutions for lithium-ion batteries recycling. Waste Manag, 2018. 76: p. 242-249.

13. $\mathrm{Xu}, \mathrm{J} .$, et al., A review of processes and technologies for the recycling of lithiumion secondary batteries. Journal of Power Sources, 2008. 177: p. 512-527. 
14. Ordoñez, J., E. Gago, and A. Girard, Processes and technologies for the recycling and recovery of spent lithium-ion batteries. Renewable and Sustainable Energy Reviews, 2016. 60: p. 195-205.

15. Gaines, L., Lithium-ion battery recycling processes: Research towards a sustainable course. Sustainable Materials and Technologies, 2018. 17: p. e00068.

16. Silveira, A.V.M., et al., Recovery of valuable materials from spent lithium ion batteries using electrostatic separation. International Journal of Mineral Processing, 2017. 169: p. 91-98.

17. Yu, J., et al., A promising physical method for recovery of LiCoO 2 and graphite from spent lithium-ion batteries: Grinding flotation. Separation and Purification Technology, 2018. 190: p. 45-52.

18. Zhang, T., et al., Characteristics of wet and dry crushing methods in the recycling process of spent lithium-ion batteries. Journal of Power Sources, 2013. 240: p. 766-771.

19. Shin, S.M., et al., Development of a metal recovery process from Li-ion battery wastes. Hydrometallurgy, 2005. 79(3-4): p. 172-181.

20. Diekmann, J., et al., Ecological Recycling of Lithium-Ion Batteries from Electric Vehicles with Focus on Mechanical Processes. Journal of The Electrochemical Society, 2017. 164(1): p. A6184-A6191.

21. $\mathrm{Li}, \mathrm{J}$. , et al., A combined recovery process of metals in spent lithium-ion batteries. Chemosphere, 2009. 77(8): p. 1132-1136.

22. He, Y., et al., Recovery of LiCoO2 and graphite from spent lithium-ion batteries by Fenton reagent-assisted flotation. Journal of Cleaner Production, 2017. 143: p. 319-325.

23. Pavoni, F.H., et al., LiCoO2 particle size distribution as a function of the state of health of discarded cell phone batteries. Powder Technology, 2018. 326: p. 7883.

24. Lee, S., J. Yang, and W. Lu, Debonding at the interface between active particles and PVDF binder in Li-ion batteries. Extreme Mechanics Letters, 2016. 6: p. 3744.

25. Vetter, J., et al., Ageing mechanisms in lithium-ion batteries. Journal of Power Sources, 2005. 147(1-2): p. 269-281.

26. Dai, C., et al., Effects of cycle times and C-rate on mechanical properties of copper foil and adhesive strength of electrodes in commercial LiCoO2 LIBs. Engineering Failure Analysis, 2019. 101: p. 193-205.

27. Standard, B., Secondary cells and batteries containing alkaline or other non-acid electrolytes - Secondary lithium cells and batteries for portable applications, in Part 3: Prismatic and cylindrical lithium secondary cells, and batteries made from them (IEC 61960-3:2017). 2017, BSI Standard Publication.

28. Yoshio, M., R.J. Brodd, and A. Kozawa, Lithium-ion batteries: science and technologies. 2010: Springer Science \& Business Media.

29. Jeschull, F., M.J. Lacey, and D. Brandell, Functional binders as graphite exfoliation suppressants in aggressive electrolytes for lithium-ion batteries. Electrochimica Acta, 2015. 175: p. 141-150.

30. Müller, M., et al., Investigation of binder distribution in graphite anodes for lithium-ion batteries. Journal of Power Sources, 2017. 340: p. 1-5.

31. Standard, B., Determination of ceratin substances in electrochemical products, in Part 5: Cadmium, lead and chromium in polymers and electronics cadmium and lead in metals by AAS, AFS, ICP-OES and ICP-MS. 2014, BSI Standard Publication.

32. Wills, B.A. and J.A. Finch, Particle Size Analysis. 2016: p. 91-107.

33. Hesse, M., O. Popov, and $\mathrm{H}$. Lieberwirth, Increasing efficiency by selective comminution. Minerals Engineering, 2017. 103-104: p. 112-126.

34. Bérubé, M.A. and J.C. Marchand, Evolution of the minerla liberation charactheristics of an iron ore undergoing grinding. International Journal of Mineral Processing, 1984. 13(3): p. 223-237. 
35. Reichert, M., et al., Research of iron ore grinding in a vertical-roller-mill. Minerals Engineering, 2015. 73: p. 109-115.

36. Leißner, T., T. Mütze, and U.A. Peuker, Nutzung der direkten Messung des Aufschlussgrades in Sortierkennfeldern. Chemie Ingenieur Technik, 2014. 86(6): p. 899-905.

37. Schubert, G. and S. Bernotat, Comminution of non-brittle materials. International Journal of Mineral Processing, 2004. 74: p. S19-S30.

38. Butt, J., H. Mebrahtu, and H. Shirvani, Microstructure and mechanical properties of dissimilar pure copper foil/1050 aluminium composites made with composite metal foil manufacturing. Journal of Materials Processing Technology, 2016. 238: p. 96-107.

39. Roundy, D., et al., Ideal Shear Strengths of fcc Aluminum and Copper. Physical Review Letters, 1999. 82(13): p. 2713-2716.

40. Beaulieu, L., et al., Colossal reversible volume changes in lithium alloys. Electrochemical and Solid-State Letters, 2001. 4(9): p. A137-A140.

41. Obrovac, M., et al., Alloy design for lithium-ion battery anodes. Journal of The Electrochemical Society, 2007. 154(9): p. A849-A855.

42. $\mathrm{Li}$, J., et al., Unravelling the Impact of Reaction Paths on Mechanical Degradation of Intercalation Cathodes for Lithium-Ion Batteries. J Am Chem Soc, 2015. 137(43): p. 13732-5.

43. Waldmann, T., et al., A mechanical aging mechanism in lithium-ion batteries. Journal of The Electrochemical Society, 2014. 161(10): p. A1742-A1747.

44. Braithwaite, J.W., et al., Corrosion of lithium - ion battery current collectors. Journal of the electrochemical society, 1999. 146(2): p. 448-456. 